\title{
Androgen Receptor Expression in an Indian Breast Cancer Cohort with Relation to Molecular Subtypes and Response to Neoadjuvant Chemotherapy - a Prospective Clinical Study
}

\author{
Akshay Anand $^{a} \quad K u l$ R. Singh ${ }^{b}$ Surender Kumar ${ }^{a} \quad$ Nuzhat Husain ${ }^{c} \quad$ Jitendra K. Kushwaha $^{a}$ \\ Abhinav A. Sonkar ${ }^{a}$ \\ a Department of Surgery, King George's Medical University, Lucknow, India; \\ ${ }^{b}$ Department of Endocrine Surgery, King George's Medical University, Lucknow, India; \\ ${ }^{\mathrm{c}}$ Department of Pathology, Ram Manohar Lohia Institute of Medical Sciences, Lucknow, India
}

\section{Keywords}

Androgen receptor - Breast neoplasm - Neoadjuvant chemotherapy $\cdot$ Clinical response $\cdot$ Molecular subtypes

\section{Summary}

Background: Breast cancer (BC) is associated with advanced presentation in developing countries like India due to various socio-economic factors. The presence of $\mathrm{BC}$ molecular subtypes such as the triple-negative (TN) subtype adds to this menace. Androgen receptor (AR) is emerging as a new biological marker. The aim of this study was to examine the prevalence of $A R$ with relation to different $\mathrm{BC}$ subtypes, and its role in predicting response to neoadjuvant chemotherapy. Methods: 116 cases of invasive BC (infiltrating ductal carcinoma, not otherwise specified) were evaluated. AR expression was correlated with clinicopathological factors, established prognostic markers, BC subtypes and it ability for predicting response to neoadjuvant chemotherapy. Results: AR was expressed in $56 \%$ of the cases. AR expression was significantly associated with early stage ( $p<0.03$ ), low axillary burden $(p<0.04)$, estrogen receptor $(p=0.002)$, progesterone receptor $(p=0.001)$ expression and luminal A molecular subtype. No significant association was observed with age, tumor size and HER2/neu status. Onethird of TNBC cases expressed AR. Higher AR expression corelated to good clinical response to neoadjuvant chemotherapy. Conclusion: AR can be utilized as a predictor of response to neoadjuvant chemotherapy especially in developing countries such as India where the load of advanced disease is high.

(c) 2017 S. Karger GmbH, Freiburg

\section{Introduction}

Breast cancer (BC) comprises a heterogeneous group of extraordinarily hormone-dependent tumors that are diverse in behavior, response to therapy, and outcome. The majority of $\mathrm{BC}$ patients (30-50\%) present with locally advanced disease [1] and are ideally managed by neoadjuvant chemotherapy (NACT) with the aim of upfront local and systemic control.

In recent years, gene expression profiling has been used to classify BC into 5 major subtypes (luminal A, luminal B, HER2 overexpressing, basal-like, and normal-like subtypes) with distant clinical outcomes [2-5]. However, a panel of immunohistochemical (IHC) markers provides clinicians with a cost-effective valid alternative to genotyping assays [6]. Although extensively reported in Western studies [7-10], data from South-Asian countries (especially India) remain limited, with anecdotal literature on the relationship between molecular subtypes as defined by IHC and clinicopathological characteristics.

Anti-estrogen therapy and targeted therapy with trastuzumab have established their role in management of $\mathrm{BC}$. Triple-negative $\mathrm{BC}$ (TNBC: estrogen receptor (ER), progesterone receptor (PR) and HER-2 neu negative) represents a unique biology that lacks any effective targeted therapies, so that a search for more biomarkers is necessary. Androgen receptor (AR) is an emerging biological marker in the field of breast carcinogenesis. Published data have indicated the presence of AR in BC tissues, most commonly in luminal $A$ and $B$ subtypes but also in approximately one-third of TNBC cases [11-13]. AR expression has also been reported in almost 50\% of ER-negative BC patients $[14,15]$ and as sole receptor in $25 \%$ of metastatic BC [16]. Nevertheless, the role of AR as a predictive or prognostic factor has not been well documented to date [13].

\section{KARGER}

\section{(๑) 2017 S. Karger GmbH, Freiburg}

Professor Abhinav Arun Sonkar, MS FACS FUICC FRCS 


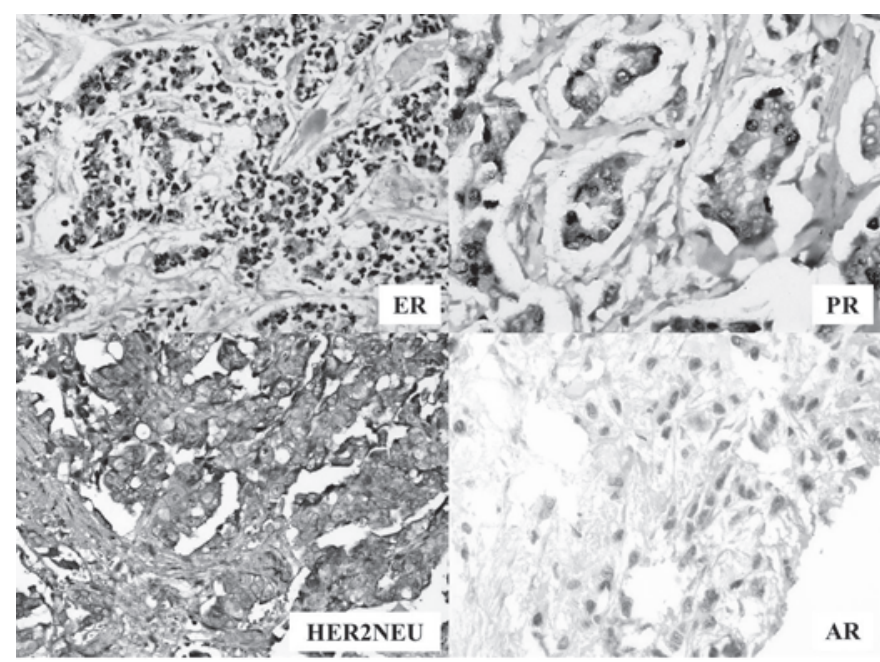

Fig. 1. Image for markers (estrogen receptor (ER), progesterone receptor (PR), HER2/neu and androgen receptor (AR)) in breast cancer.

This current study was conducted to investigate the prevalence of $\mathrm{AR}$ positivity in invasive $\mathrm{BC}$ in an Indian cohort, the association of AR with various clinicopathological factors, established prognostic markers and molecular subtypes, and the role of AR in predicting response to NACT.

\section{Methods}

Study Subjects and Inclusion Criteria

A prospective analysis was done at Department of General Surgery, King George's Medical University, Uttar Pradesh (UP) in collaboration with Department of Pathology RML Institute of Medical Sciences, UP, from August 2011 to December 2012. All females with unilateral BC who underwent upfront surgery or received NACT according to the NCCN treatment guidelines were included after proper written consent and ethical clearance from the Institutional Ethics committee.

\section{IHC Staining of $A R, E R, P R$ and HER2/neu and Subtype Definition}

We evaluated AR, ER, PR and HER2/neu expression in specimens from formalin-fixed, paraffin-embedded Tru-cut biopsy tissue using IHC. Primary antibodies for AR (monoclonal, clone F39.4.1; Biogenex, diluted 1:50), ER (monoclonal, clone 6F11; Novocastra, 1:50 dilution), PR (monoclonal, clone PgR 312/2; Novocastra, 1:50 dilution) and HER2/neu (polyclonal; Dako, diluted 1:500) were used.

The thresholds suggested by the 2011 ASCO/CAP guidelines for ER/PR and the 2007 ASCO/CAP guidelines for HER2/neu interpretation were used. 2011 ASCO/CAP guidelines were applied for AR and considered at least $1 \%$ nuclear staining of any intensity (1+ to $3+$ ) as a positive AR assay (fig. 1).

In this study, we opted for a simple classification based on the expressions of ER, PR and HER2 $[6,17]$. BC was classified into 4 subtypes: luminal A (ER+ and/or PR+, HER2-); luminal B (ER+ and/or PR+, HER2+); triple negative (ER-, PR-, HER2-) and HER2/neu enriched (ER-, PR-, HER2+).

\section{Assessing Response to NACT}

Patients with locally advanced BC (stage IIIb or above) were subjected to NACT (FEC followed by docetaxel chemotherapy: 5-fluorouracil $500 \mathrm{mg} / \mathrm{m}$ intravenously (IV) day 1, epirubicin $100 \mathrm{mg} / \mathrm{m}$ IV day 1, cyclophosphamide $500 \mathrm{mg} / \mathrm{m}$ IV day 1 , cycled every 21 days for 3 cycles; followed by docetaxel $100 \mathrm{mg} / \mathrm{m}$ IV day 1 , cycled every 21 days for 3 cycles) to downstage the tumor. For assessing the response, patients were evaluated on the basis of WHO clini- cal response criteria; first prior to 1st cycle and re-evaluated after completion of 4 th cycle of chemotherapy. Patients showing partial or complete response were grouped as 'responders', whereas progressive or stable disease was grouped as 'non-responders'.

\section{Statistical Analysis}

All data were analyzed using the SPSS 16.0 statistical software package. The chi square and Fisher's exact probability tests were used to analyze the differences between qualitative data. $\mathrm{p}$ values below 0.05 were considered significant.

\section{Results}

\section{Patient and Treatment Characteristics}

Of $131 \mathrm{BC}$ patients, 116 fulfilled the inclusion criteria and were assessed. The mean age of patients at the time of presentation/diagnosis was $47.6 \pm 10.1$ years (range $20-77$ years, median 48 years); 20 were diagnosed with $\mathrm{BC}$ before the age of 35 (mean age $31.8 \pm 4.4$ years; median 34 years) and were considered as 'young age'.

Histologically, all patients had infiltrating ductal carcinoma, not otherwise specified (IDC-NOS). Since in majority of patients, core tissue biopsy was performed using Tru-cut as a part of triple assessment, grade was not commented in the pathological report.

\section{Relationship between AR Status and Clinicopathological Data}

Table 1 shows the correlations between AR expression and clinicopathological factors. AR was expressed in 65 patients (56\%). AR expression showed negative correlation with overall stage $(\mathrm{p}<0.03)$ and axillary lymph node status $(\mathrm{p}<0.04)$. No statistically significant association of AR expression was observed with age or tumor size.

\section{Relationship between AR Status and Other Hormonal Markers}

AR expression correlated significantly with ER $(\mathrm{p}=0.002)$ and $\mathrm{PR}(\mathrm{p}=0.001)$ expression. It was also significantly increased in hormonal receptor-positive $\mathrm{BC}$ (ER and/or PR positive) in comparison to hormonal receptor-negative $\mathrm{BC}$ (ER and $\mathrm{PR}$ negative) (70.2\% vs. $42.4 \%, \mathrm{p}=0.002)$. No statistically significant association of AR expression was observed with HER2/neu status.

\section{Relationship between AR Status and BC Subtypes}

Maximum positivity with significant association was shown with luminal A subtype (77.8\%). Even TNBC showed positivity for AR (30\%). In particular, in 'young' BC patients the AR expression was increased among all subtypes including hormone receptornegative subgroups.

\section{Relationship between AR Status and Response to NACT}

Among patients who were offered NACT, the majority (47; 65.3\%) showed partial response to chemotherapy, with 12 patients (16.7\%) showing complete response. AR expression was higher in responders as compared to non-responders ( $\mathrm{p}=0.218)$. 24 of 30 patients (80\%) with TNBC were given NACT, of whom 7 (29.1\%) were AR positive. AR-positive TNBC showed a better response to NACT since 5 of these $7(71 \%)$ were partial or complete responders compared with 3 of the 17 (17.6\%) AR-negative TNBC patients. 
Table 1. General characteristics of study population and correlation between AR expression and clinicopathological factors

\begin{tabular}{|c|c|c|c|}
\hline Characteristics & $\mathrm{n}(\%)$ & AR positivity & $\mathrm{p}$ value \\
\hline \multicolumn{4}{|l|}{ Age $(n=116)$} \\
\hline$\leq 35$ years & $20(17.2)$ & $15(75.0)$ & \multirow[t]{2}{*}{0.06} \\
\hline$>35$ years & $96(82.8)$ & $50(52.1)$ & \\
\hline \multicolumn{4}{|c|}{ Relation with ER, PR and HER2/neu status } \\
\hline ER+ & $54(46.6)$ & $39(72.2)$ & \multirow[t]{2}{*}{$<0.001$} \\
\hline ER- & $62(53.4)$ & $26(41.9)$ & \\
\hline $\mathrm{PR}+$ & $46(39.7)$ & $34(73.9)$ & \multirow[t]{2}{*}{$<0.002$} \\
\hline PR- & $70(60.3)$ & $31(44.3)$ & \\
\hline HER $2+$ & $58(50.0)$ & $35(60.3)$ & \multirow[t]{2}{*}{0.349} \\
\hline HER2- & $58(50.0)$ & $30(51.7)$ & \\
\hline \multicolumn{4}{|c|}{ Relation with breast cancer subtypes (in all ages) $(\mathrm{n}=116)$} \\
\hline Luminal A & $27(23.3)$ & $21(77.8)$ & \multirow[t]{4}{*}{0.003} \\
\hline Luminal B & $30(25.9)$ & $19(63.3)$ & \\
\hline HER2/neu enriched & $29(25.0)$ & $16(55.1)$ & \\
\hline Triple negative & $30(25.8)$ & $9(30)$ & \\
\hline \multicolumn{4}{|c|}{ Relation with breast cancer subtypes (in age $\leq 35$ years) $(\mathrm{n}=20)$} \\
\hline Luminal A & $8(40.0)$ & $7(87.5)$ & \multirow[t]{4}{*}{0.099} \\
\hline Luminal B & $5(25.0)$ & $5(100.0)$ & \\
\hline HER2/neu enriched & $5(25.0)$ & $2(40.0)$ & \\
\hline Triple negative & $2(10.0)$ & $1(50.0)$ & \\
\hline \multicolumn{4}{|c|}{ Relation with breast cancer subtypes (in age $>35$ years) $(\mathrm{n}=96)$} \\
\hline Luminal A & $19(19.8)$ & $14(73.6)$ & \multirow[t]{4}{*}{0.016} \\
\hline Luminal B & $25(26.0)$ & $14(56.0)$ & \\
\hline HER2/neu enriched & $24(25.0)$ & $14(58.3)$ & \\
\hline Triple negative & $28(29.2)$ & $8(28.6)$ & \\
\hline \multicolumn{4}{|l|}{ Overall stage $(n=116)$} \\
\hline II & $33(28.5)$ & $23(69.7)$ & \multirow[t]{3}{*}{0.034} \\
\hline III & $80(68.9)$ & $42(52.5)$ & \\
\hline IV & $3(2.6)$ & $0(0)$ & \\
\hline \multicolumn{4}{|l|}{ Tumor size $(\mathrm{n}=116)$} \\
\hline $\mathrm{T} 2$ & $26(22.4)$ & $17(65.4)$ & \multirow[t]{3}{*}{0.059} \\
\hline T3 & $22(18.9)$ & $16(72.7)$ & \\
\hline $\mathrm{T} 4$ & $68(58.7)$ & $32(47.1)$ & \\
\hline \multicolumn{4}{|l|}{ Nodal stage $(\mathrm{n}=116)$} \\
\hline N0 & $33(28.4)$ & $24(72.7)$ & \multirow[t]{4}{*}{0.042} \\
\hline $\mathrm{N} 1$ & $57(49.1)$ & $31(54.3)$ & \\
\hline $\mathrm{N} 2$ & $21(18.1)$ & $7(33.3)$ & \\
\hline N3 & $5(4.4)$ & $3(60)$ & \\
\hline \multicolumn{4}{|c|}{ Response to NACT $(\mathrm{n}=72)$} \\
\hline Progressive disease & $7(9.7)$ & $2(28.6)$ & \multirow[t]{4}{*}{0.218} \\
\hline Stable disease & $6(8.3)$ & $1(16.7)$ & \\
\hline Partial response & $47(65.3)$ & $26(55.3)$ & \\
\hline Complete response & $12(16.7)$ & $6(50.0)$ & \\
\hline
\end{tabular}

$\mathrm{AR}=$ androgen receptor, $\mathrm{ER}=$ estrogen receptor $\mathrm{PR}=$ progesterone receptor, $\mathrm{NACT}=$ neoadjuvant chemotherapy.

\section{Discussion}

Expression of ER, PR and HER2/neu as predictive and/or prognostic markers in $\mathrm{BC}$ development has led to a paradigm shift in treatment approach to targeted chemotherapy regimens [18-21]. AR is highly expressed in all BCs (60-70\%), irrespective of ER status [22-24], but its definite role remains to be established. Various publications document the AR expression as ranging from 43 to $75 \%$ in different cohorts [12, 25-29]. Moinfar et al. [28] found $60 \%$ of all invasive carcinomas and $46 \%$ of ER-negative invasive carcinomas to be AR positive. In a study from India, Mishra et al. [30] reported the prevalence to be $40 \%$. The results of our study are in agreement with these publications, showing that AR was expressed in $56 \%$ of invasive BC cases. It has also been shown that AR is more frequently expressed in particular histological types of $\mathrm{BC}$, more commonly in IDC-NOS, and with less frequency in other histopathological types [30,31]. Our study showed that more than half of patients with IDC-NOS expressed AR. These results were somewhat limited in our study since all patients showed IDC-NOS on histopathology. Our results show that AR expression is associated with lower axillary nodal burden and early AJCC stage. These findings are supported by previous studies indicating that AR expression is related to good prognostic factors, including lower histological grade, smaller tumor size and negative nodal metastasis [32-34]. The expression was higher in young age and early (T2 and T3) tumor size, but relation of AR with age and tumor size was statistically insignificant. Another limitation of our study was that we did not determine the relationship with grade and Ki67 proliferation index.

In the present work $\mathrm{AR}$ expression was also associated with ER and PR positivity (good prognostic factors), in accordance with Park et al. [25] and Ana et al. [26]. However, a significant percentage of ER- and PR-negative tumors showed AR positivity, which has also been reported by Seung et al. [32] and Ana et al. [26]. This information may represent the independent expression of $A R$ in $\mathrm{BC}$ and also demonstrate that the presence of AR expression in ERnegative tumors has a particular prognostic significance. AR positivity did not significantly correlate with loss of HER2/neu expression, with HER2/neu-enriched ER/PR-negative tumors showing AR positivity in $42.4 \%$. Micello et al. [35] reported a $77 \%$ expression rate in HER2-positive BC. This observation may be used as a good additional target therapy for this subgroup of patients. Laboratory studies have shown inhibitory roles of androgens analogues on ER-negative/AR-positive cells lines. Similar approaches can be used for ER-negative/AR-positive BC as an adjunctive therapy [27].

In TNBC, chemotherapy is the main adjuvant treatment with an inferior survival. New biomarkers and additional effective treatment strategies need to be explored to improve prognosis in this subset of patients. Safarpour et al. [36] in a recent analysis of AR as a routine assessment in $\mathrm{BC}$ tabulated 22 studies reporting the percentage of TNBC in range of 7-60\%. These TNBC were mainly of high histological grade, showed a high mitotic index, and were found more frequently in premenopausal women. Xiang et al. [33] showed that TNBC could be divided into a good and a poor prognosis subtype according to AR status. Since AR is expressed in large proportion of TNBC, it might have a role as a prognostic marker and a therapeutic target in this subgroup [18]. In our study, $30 \%$ of TNBC cases showed AR positivity. Collins et al. [37] in a Nurse Health study reported that, despite being considered hormonally unresponsive, $32 \%$ of basal-like cancers expressed AR. Sa- 
farpour et al. [36], while highlighting the fraction of tumors with positive AR among TNBC cases (6.6-75\%), made a startling observation that only a fourth of the studies they discussed had used the most recent ASCO/CAP guidelines. If a threshold of $\geq 1 \%$ were used, the percentage of AR-positive cases would increase and at least these TNBC could also form a subset for targeted therapy.

Exploring role of AR expression in predicting response to NACT in locally advanced $\mathrm{BC}$, this study showed that AR was more expressed in patients who were good clinical responders. Mishra et al. [30] and Chintamani et al. [38] have documented that AR status predicts response to chemotherapy in the neoadjuvant setting, and AR can serve as independent predictor of response to NACT.

The prevalence of hormone receptor-positive $\mathrm{BC}$ in Asian countries has been found to be lower than the Western world. Western studies have reported 70-80\% ER and 60-70\% PR expression in BC, respectively [39-42]. In Indian cohort, Desai et al. [43] documented a prevalence of $32.6 \%$ for ER-positive and $46.1 \%$ for PR-positive BC. A recent study from Mumbai has also showed that hormone receptor expression in India is lower compared to the
West [44]. A study from the northern part of India showed that HER2/neu overexpression is higher (46.37\%) in comparison to $25-30 \%$ shown in most Western literature [45]. Our study results correlate with the reported literature and highlight the fact that, in India, $\mathrm{BC}$ stands apart in terms of clinicopathological features from the Western world.

In conclusion, $\mathrm{AR}$ is expressed in a significant percentage of $\mathrm{BC}$ cases. AR is also associated with a lower disease burden and favorable established prognostic markers. In addition, AR is expressed in a significant number of TNBC and HER2/neu-positive cancers, and these particular ER-negative patients may benefit from an additional targeted therapy. AR may also be utilized as a predictor of response to NACT, especially in country such as India where the load of locally advanced BC is high.

\section{Disclosure Statement}

All authors declare that they have no conflict of interests.

\section{References}

1 Chintamani, Singh JP, Mittal MK, et al.: Role of p-glycoprotein expression in predicting response to neoadjuvant chemotherapy in breast cancer - a prospective clinical study. World J Surg Oncol 2005;3:61.

2 Perou CM, Jeffrey SS, van de Rijn M, et al.: Distinctive gene expression patterns in human mammary epithelial cells and breast cancers. Proc Natl Acad Sci USA 1999;96:9212-9217.

3 Sørlie T, Perou CM, Tibshirani R, et al.: Gene expression patterns of breast carcinomas distinguish tumor subclasses with clinical implications. Proc Natl Acad Sci USA 2001;98:10869-10874.

4 Sorlie T, Tibshirani R, Parker J, et al.: Repeated observation of breast tumor subtypes in independent gene expression data sets. Proc Natl Acad Sci USA 2003;100: 8418-8423.

5 Brenton JD, Carey LA, Ahmed AA, Caldas C: Molecular classification and molecular forecasting of breast cancer: Ready for clinical application? J Clin Oncol 2005;23:7350-7360.

6 Tang P, Wang J, Bourne P: Molecular classifications of breast carcinoma with similar terminology and different definitions: Are they the same? Hum Pathol 2008; 39:506-513

7 Cui X, Schiff R, Arpino G, et al.: Biology of progesterone receptor loss in breast cancer and its implications for endocrine therapy. J Clin Oncol 2005;23:7721-7735.

8 Early Breast Cancer Trialists' Collaborative Group: Effects of chemotherapy and hormonal therapy for early breast cancer on recurrence and 15-year survival: An overview of the randomised trials. Lancet 2005;365: 1687-1717.

9 Braga S, dal Lago L, Bernard C, et al.: Use of trastuzumab for the treatment of early stage breast cancer. Expert Rev Anticancer Ther 2006;6:1153-1164.

10 Piccart-Gebhart MJ, Procter M, Leyland-Jones B, et al.: Trastuzumab after adjuvant chemotherapy in HER2positive breast cancer. N Engl J Med. 2005;353:16591672.

11 Shidham VB, Komorowski RA, Machhi JK: Androgen receptor expression in metastatic adenocarcinoma in females favors a breast primary. Diagn Pathol 2006;1:34.
12 Gonzalez LO, Corte MD, Vazquez J, et al.: Androgen receptor expression in breast cancer: Relationship with clinicopathological characteristics of the tumors, prognosis, and expression of metalloproteases and their inhibitors. BMC Cancer 2008;8:149.

13 Riva C, Dainese E, Caprara G, et al.: Immunohistochemical study of androgen receptors in breast carcinoma. Evidence of their frequent expression in lobular carcinoma. Virchows Arch 2005;447:695-700.

14 Nahleh Z: Androgen receptor as a target for the treatment of hormone receptor-negative breast cancer: An unchartered territory. Future Oncol 2008;4:15-21.

15 Agoff SN, Swanson PE, Linden H, et al.: Androgen receptor expression in estrogen receptor-negative breast cancer. Immunohistochemical, clinical, and prognostic associations. Am J Clin Pathol 2003;120:725-731.

16 Lea OA, Kvinnsland S, Thorsen T: Improved measurement of androgen receptors in human breast cancer. Cancer Res 1989;49:7162-7167.

17 Pestalozzi B, Castiglione M: Primary breast cancer: ESMO Clinical Recommendations for diagnosis, treatment and follow-up. Ann Oncol 2008;19:ii7-ii10.

18 Berry DA, Cronin KA, Plevritis SK, et al.: Effects of screening and adjuvant therapy on mortality from breast cancer. N Engl J Med 2005;353:1784-1792.

19 de Bono JS, Tolcher AW, Rowinsky EK: The future of cytotoxic therapy: Selective cytotoxicity based on biology is the key. Breast Cancer Res 2003;5:154-159.

20 Maximov PY, Lee TM, Jordan VC: The discovery and development of selective estrogen receptor modulators (SERMs) for clinical practice. Curr Clin Pharmacol 2013;8:135-155.

21 Slamon D, Eiermann W, Robert N, et al.: Adjuvant trastuzumab in HER2-positive breast cancer. N Engl J Med. 2011;365:1273-1283.

22 Gucalp A, Traina TA: Triple-negative breast cancer: Role of the androgen receptor. Cancer J 2010;16:62-65.

23 Shah PD, Gucalp A, Traina TA: The role of the androgen receptor in triple-negative breast cancer. Womens health (Lond) 2013;9:351-360.
24 Peters AA, Buchanan G, Ricciardelli C, et al.: Androgen receptor inhibits estrogen receptor-alpha activity and is prognostic in breast cancer. Cancer Res 2009;69: 6131-6140.

25 Park S, Koo J, Park HS, et al.: Expression of androgen receptors in primary breast cancer. Ann Oncol 2010; 21:488-492.

26 Gonzalez-Angulo AM, Stemke-Hale K, Palla SL, et al.: Androgen receptor levels and association with PIK3CA mutations and prognosis in breast cancer. Clin Cancer Res 2009;15:2472-2478.

27 Niemeier LA, Dabbs DJ, Beriwal S, et al.: Androgen receptor in breast cancer: Expression in estrogen receptor-positive tumors and in estrogen receptor-negative tumors with apocrine differentiation. Mod Pathol 2010;23:205-512.

28 Moinfar F, Okcu M, Tsybrovskyy O, et al.: Androgen receptors frequently are expressed in breast carcinomas: Potential relevance to new therapeutic strategies. Cancer 2003;98:703-711.

29 Agrawal AK, Jeleń M, Grzebieniak Z, et al.: Androgen receptors as a prognostic and predictive factor in breast cancer. Folia Histochem Cytobiol 2008;46:269-276.

30 Mishra AK, Agrawal U, Negi S, et al.: Expression of androgen receptor in breast cancer and its correlation with other steroid receptors and growth factors. Indian J Med Res 2012;135:843-852.

31 Alshenawy HA: Prevalence of androgen receptors in invasive breast carcinoma and its relation with estrogen receptor, progesterone receptor and Her2/neu expression. J Egypt Natl Cancer Inst 2012;24:77-83.

32 Koo JS, Jung W, Jeong J: The predictive role of E-cadherin and androgen receptor on in vitro chemosensitivity in triple-negative breast Cancer. Jpn J Clin Oncol 2009;39:560-568.

33 Luo X, Shi YX, Li ZM, Jiang WQ: Expression and clinical significance of androgen receptor in triple negative breast cancer. Chin J Cancer 2010;29:585-590.

34 Ogawa Y, Hai E, Matsumoto K, et al.: Androgen receptor expression in breast cancer: Relationship with clinicopathological factors and biomarkers. Int J Clin Oncol 2008;13:431-435 
35 Micello D, Marando A, Sahnane N, et al.: Androgen receptor is frequently expressed in HER2-positive, ER PR-negative breast cancers. Virchows Arch 2010;457: 467-476.

36 Safarpour D, Pakneshan S, Tavassoli FA: Androgen receptor (AR) expression in 400 breast carcinomas: Is routine AR assessment justified? Am J Cancer Res 2014;4:353-368.

37 Collins LC, Cole KS, Marotti JD, et al.: Androgen receptor expression in breast cancer in relation to molecular phenotype: Results from the Nurses' Health Study. Mod Pathol 2011;24:924-931.

38 Chintamani, Kulshreshtha P, Chakraborty A, et al.: Androgen receptor status predicts response to chemotherapy, not risk of breast cancer in Indian women. World J Surg Oncol 2010;8:64.
39 Ambroise M, Ghosh M, Mallikarjuna VS, Kurian A: Immunohistochemical profile of breast cancer patients at a tertiary care hospital in South India. Asian Pac J Cancer Prev 2011;12:625-629.

40 Li CI, Daling JR, Malone KE: Incidence of invasive breast cancer by hormone receptor status from 1992 to 1998. J Clin Oncol 2003;21:28-34.

41 Horii R, Akiyama F, Ito Y, Iwase T: Assessment of hormone receptor status in breast cancer. Pathol Int 2007; 57:784-790.

42 Jirström K, Rydén L, Anagnostaki L, et al.: Pathology parameters and adjuvant tamoxifen response in a randomised premenopausal breast cancer trial. J Clin Pathol 2005;58:1135-1142.
43 Desai SB, Moonim MT, Gill AK, et al.: Hormone receptor status of breast cancer in India: A study of 798 tumours. Breast 2000;9:267-270; discussion 270.

44 Shet T, Agrawal A, Nadkarni M, et al.: Hormone receptors over the last 8 years in a cancer referral center in India: What was and what is? Indian J Pathol Microbiol 2009;52:171-174.

45 Kumar V, Tewari M, Singh U, Shukla HS: Significance of Her-2/neu protein over expression in Indian breast cancer patients. Indian J Surg 2007;69:122-128. 